\title{
A New Formulation of the Frequency Factor in the Expression for the Rate Constant of Interfacial Charge Transfers
}

\author{
Jaime González Velasco* \\ Universidad Autónoma de Madrid. Facultad de Ciencias. Cantoblanco.28049 Madrid. Spain
}

Received 20 July 2006; accepted 17 July 2007

\begin{abstract}
A new way for deriving the fundamental equation of the electrochemistry has been developed in the potential range in which Butler-Volmer behaviour is found. In this approach the frequency factor is considered to be a function of the potential instead of the activation energy. The frequency factor is calculated by means of a classical statistical mechanics treatment giving rise to a new definition for the symmetry factor. A new expression for the standard rate constant in adiabatic heterogeneous charge transfer reactions has been derived.
\end{abstract}

Keywords: heterogeneous charge transfer, standard rate constant, potential dependent frequency factor.

\section{Introduction}

Although the first attempt to give a theoretical explanation of the kinetic aspects of interfacial charge transfer was made in the early thirties [1], plenty of different and important contributions have been made since then and are made in the present. An account of the main contributions to the theory of electron transfers can be found in different general works [2-6]. Marcus and Hush [7,8] made the first systematic work on the so called [9] outer sphere electron transfers, which behave, at the electrode-electrolyte interphase, as first order heterogeneous reactions. The first work in which a frequency factor was deduced with the adequate dimensions for a first order heterogeneous reaction $\left(\mathrm{cms}^{-1}\right)$ was made by Evans and Hush [10] who assumed the transition state formalism and deduced a frequency factor $\mathrm{A}=\left\{\frac{k_{B} T}{2 \pi \mathrm{m}}\right\}^{1 / 2}$ (where $\mathrm{k}_{\mathrm{B}}$ represents the Boltzmann constant and $\mathrm{m}$ the mass of a molecule or ion (the electroactive substance)) with the

\footnotetext{
*Corresponding author. E-mail address: Jaime.gonzalez@uam.es
} 
demanded dimensions and an order the magnitude, depending on $\mathrm{T}$ and $\mathrm{m}$, of around $10^{4} \mathrm{cms}^{-1}$. A previous deduction of the fundamental equation of the Electrochemistry was made by Frumkin after considering a work of Bronsted and Pedersen [11] on the dissociation of a homologous series of organic acids. Frumkin had the intuition [12] to consider the behaviour of a redox system at different potentials as parallel to the behaviour described by the former two authors. The variation of a thermodynamic magnitude, the free energy for the hydrogen dissociation reaction in the homologous series of organic acids, was experimentally found to be linearly related with the variation of a kinetic magnitude, like the activation energy for the proton transfer from the molecules of acid to water molecules. Frumkin thought that a redox system at different potentials behaved like a homologous series of substances by considering that the free energy of reaction from the oxidized to the reduced form can be linearly changed with that potential, and, consequently, he established that the variation of the activation energy for the redox charge transfer was linearly related with the free energy of reaction, i. e., with the potential difference across the interphasial zone times the electric charge of the particle involved. By using this relationship Frumkin could deduce the exponential dependence experimentally found to exist (or the equivalent logarithmic expression experimentally established by Tafel [13]) between current density, $\mathrm{j}$, and the applied potential in Redox electrode processes. Horiuti and Polanyi [14] were the first to apply the transition state theory to make the theoretical interpretation of an electrodic reaction. The link between the change in the electrochemical free energy of reaction, expressed by:

$$
\Delta(\Delta \mathrm{G})=\mathrm{z} \mathrm{e}_{0} \Delta \varphi
$$

(where $\mathrm{z}$ represents the number of electrons transferred (one in an unique electron transfer event), $\mathrm{e}_{0}$ is the charge of the electron and $\Delta \varphi$ the Galvani's or absolute potential difference through the interphasial region), and the change in the activation energy for interfacial electron transfers is established by introducing the so called symmetry factor, $\beta$, so that:

or

$$
\Delta\left(\Delta \mathrm{G}^{*}\right)=\beta \Delta(\Delta \mathrm{G})=\beta \mathrm{z} \mathrm{e} \mathrm{e}_{0} \Delta \varphi
$$

$$
\Delta \mathrm{G}^{*}(\mathrm{E})=\Delta \mathrm{G}^{*}{ }_{0}+\beta z \mathrm{~F}\left(\mathrm{E}-\mathrm{E}^{0 \prime}\right)
$$

where $\Delta \mathrm{G}^{*}{ }_{0}$ represents the activation energy measured at the formal potential, $\mathrm{E}^{0}$. $\mathrm{E}$ represents the value of the potential difference across the double layer measured with respect to any reference electrode, with $\mathrm{E}=\Delta \varphi+\mathrm{E}^{*}$, where $\mathrm{E}^{*}$ represents the unknown absolute potential difference across the double layer of the reference electrode and $\mathrm{E}^{0 \text { r }}$ the so called formal potential [15].

Thus, according to the Frumkin formulation, there exists a linear relation between the activation energy for electron transfer reactions and the potential value, and the proportionality coefficient is the symmetry factor, $\beta$, which for monoelectronic electron transfers coincides with the transfer coefficient. 
Consequently, the rate constant for electron transfers between electrode and electrolyte results to show an exponential relation to the potential value through the expressed dependence existing between $\Delta \mathrm{G}^{*}$ and $\mathrm{E}, \mathrm{i}$. e,:

$$
k(E)=\kappa \mathrm{Z} \exp \left(-\frac{\Delta \mathrm{G}^{*}(E)}{R T}\right)
$$

where $\kappa$ represents the transmission coefficient and $\mathrm{Z}$ the frequency factor (which is a function of the temperature, but not of the potential). According to the model based on the relations deduced by Bronsted, a determination of $\Delta \mathrm{G}^{*}$ from the cut of the energy curves representing the oxidized and reduced states of the Redox couple, allowed to expect a variation of $\beta$ with $E$, more accentuated the closer the cutting point of the energy surfaces is situated with respect to the minimum of the energy states representing the oxidised and the reduced form of the redox couple. Likewise, the definition of $\Delta \mathrm{G}^{*}$ for electrode-electrolyte charge transfers made by Marcus lead to a quadratic relationship between the activation energy and the potential and, therefore, to a linear rate of change of $\beta$ with the potential, expressed by the following equation:

$$
\left(\frac{\partial \beta}{\partial E}\right)_{T}=\frac{F E}{2 \lambda}=\frac{F \eta}{2 \lambda}=\frac{e_{0} \eta}{2 \lambda(e V)}
$$

where $\lambda$ represents the reorganization energy of the solvation shell in the electroactive substances and is related with the activation energy according to the equation. According to Eq. 5, the variation of $\beta$ to be expected in the Redox couple $\left[\mathrm{Fe}(\mathrm{CN})_{6}\right]^{3-/ 4-}$ (for a value of $\lambda=119.4 \mathrm{~kJ} / \mathrm{mol}$ (or $\lambda=\lambda_{\mathrm{i}}+\lambda_{0}=(0.379+$ $0.860) \mathrm{eV}=1.239 \mathrm{eV}$, see for instance Ref. [16]) should be of around 0.4 per Volt, or 0.1 in $250 \mathrm{mV}$. It is not easy to study any simple reaction transfer without interference of any other parallel reaction across a sufficiently wide potential range, at least in aqueous solutions, which explains that only few works seem to have successfully proved the validity of this prediction. Thus, Savéant and Tessier [17] studied the electron transfer in four different organic substances at a dropping mercury electrode (DME) and found that the transfer coefficient accomplished, within the experimental error, Eq. 5. On the other hand, Gileadi et al. [18] carried out systematic studies on the hydrogen evolution reaction on the DME. They found that the Tafel line obtained for that reaction remained perfectly straight over a potential range of $0.6-0.7 \mathrm{~V}$ corresponding to a variation in 4-5 orders of magnitude in the current function. This represents the larger potential range studied without any interference of parallel reactions and correcting the diffuse double layer according to the Frumkin's theory [19]. The result was repeatedly observed at different temperatures so that the authors came to the conclusion that the transfer coefficient was strictly independent of the potential. Analogous results were found by the same authors [20] for the reduction of bromate on a DME. Thus, it can be concluded that the linear dependence of $\beta$ with the potential resulting from assuming a potential 
dependence on the activation energy, is, at least until the moment, a controversial unresolved problem from the point of view of the experimental evidence.

It has been always admitted that the potential dependence of the reaction rate is a consequence of the linear (according to Frumkin) or quadratic (according to Marcus) dependence of the activation energy on the potential, where the consequence of this idea is that $\beta$ varies linearly with the potential. These theories do not take into account the electronic structure of the electrode. A more general approach to the problem has been made by taking into account the electronic states in the electrode close to the Fermi level as well as the density of electronic states. The general equation deduced can be approximately solved for three different potential ranges (see for instance Chapter VI in [4]). When the condition $\lambda>\left|e_{0} \eta\right|$ is accomplished, where $e_{0}$ represents the charge of the electron and $\eta$ the overpotential, the classical Butler-Volmer behaviour is found. At very large overpotentials a limiting current is predicted and at a third potential range an erfc relation between $j$ and $\eta$ is found.

All these ideas are valid as long as the electroactive substances are of ionic nature and, therefore inner- and outer- solvation shells are present. Nonetheless, many of the most interesting electrochemical reactions of practical interest, like the hydrogen evolution reaction, or the hydrogen oxidation, or water oxidation to hydrogen peroxide or oxygen, or oxygen evolution, or electropolymerizations, or electrosynthetic routes to obtain different organic or inorganic substances, etc., are characterized by the presence of electroactive substances in the OHP or in the adsorbed layer (IHP = Inner Helmholtz Plane) which are electrically neutral in nature and, therefore they can only weakly interact with the solvent molecules through Van der Waal's interactions or by formation of hydrogen bridges, if possible. In these cases, the free energies associated to the reorganization of the solvation shell cannot be influenced by variations in the interphasial potential difference. Also the rates of interfacial electron transfers through the so called weakly $\pi$-conjugated spacers [21] follow typical current-potential relationships with values of the standard rate constant that decrease exponentially with the spacer length. The authors of this work studied charge transfers through separations of up to around $25 \AA$, i. e., a distance longer than the width of the double layer at which the electric field acting in the double layer region would be rather weakened due to the shielding effect exerted by different molecules or ions interposed between the electrode surface and the electroactive center. However, the electrochemical processes above mentioned are also characterized by exponential relationships between current density and overvoltage, whose theoretical justifications are based in the ideas developed by the authors cited. Nonetheless, it would be difficult to argue that the activation energy, expressed as a function of the reorganization energy of the solvation shell, is a function of the potential difference through the double layer, for electroactive groups that can be located as far from the double layer region as 25 or more $\AA$.

In order to try to overcome some of the inconsistencies above discussed, a new approach is made to the deduction of the fundamental equation of the Electrochemistry based in considering that the potential dependence is introduced in the rate equation by the potential dependence of the frequency factor, $\mathrm{Z}(\mathrm{E})$, 
instead by considering that the activation energy is a function of E. Thus, according to this, the new expression for the electrochemical rate constant can be given by:

$$
k=\kappa Z(E) \exp \left(-\frac{\Delta G^{*}}{R T}\right)
$$

$\mathrm{Z}$ (E) is obtained in this work following a classical statistical mechanics treatment. The approach made allows to obtain the exponential relation between the current, $j$, and the overpotential, $\eta$, within the potential range in which Tafel behaviour is expected, i. e., only the situation is considered in which the condition $\lambda>>\left|e_{0} \eta\right|$ is accomplished. The energy of the electroactive substance participating in the charge transfer process is considered by defining the partition function of the reacting particles in the Outer Helmholtz Plane (OHP) and considering the contribution made to it by the electrical energy when the electroactive substance enters the interphasial region (which is equivalent to express the free energy of the molecular redox levels in electric unities). In this way, an expression for the frequency factor $(Z)$ in the rate constant equation is obtained in which $Z$ results to be an exponential function of the potential. The new equation for $Z$ is demonstrated to lead to the fundamental equation of the Electrochemistry. The activation free energy, $\Delta \mathrm{G}^{*}$, will be calculated by the dynamics of solvent relaxation, respecting the model of the activated complex, like in the case of the Marcus-Hush theory, but the energy of the redox couple, and, therefore the energy of the activated complex is supposed not to be influenced by electric field acting inside the interfacial region. On the other hand, the theory which leads to the theoretical description of the transmission coefficient, $\kappa$, is discussed in other works (see, for instance [3] and References therein), since the model discussed in this work is valid for adiabatic charge transfer processes in which $\kappa=1$.

The following sections are dedicated to theoretically justify the exponential dependence of $\mathrm{Z}$ with the interfacial potential, and, based on the same, to deduce the so-called fundamental equation of the electrochemistry [15] within the potential range in which a Butler-Volmer behaviour is experimentally found. In order to reach this goal a phenomenological mechanical statistic approach is followed.

\section{The definition of $Z$ as the thermal velocity of the reacting particles [22] (electroactive substances)}

The system to be studied is of the type: $\mathrm{O}+$ ne $\rightarrow \mathrm{R}$, where the electroactive substances are in much smaller concentrations than the supporting electrolyte, so that the whole migratory transport can be supposed to be carried out by the ions components of it. On the other hand, the total concentration of ions in the electrolyte is high enough to admit a Helmholtz rigid double layer model to be valid, which supposes to admit a variation linear of potential across this region. 
Furthermore, no specific adsorption of any species present in the solution takes place. The initial situation of the system is a potential difference corresponding to the formal potential. $\mathrm{E}^{0}$, at which a homogeneous profile for the concentrations (no variation of the concentrations of $\mathrm{O}$ and $\mathrm{R}$ with the distance $\mathrm{x}$ to the electrode surface) will prevail, and where the average energy of the redox molecular levels is equal to the energy of the Fermi level in the electrode. Likewise, the rate of the diffusive transport of the electroactive substances is supposed to be much higher than the rate of the charge transfer reaction so that the initial concentration profiles will be approximately maintained throughout the whole potential range of the study. The distance $\mathrm{x}$ is taken as perpendicular to the electrode surface (supposed to be an ideal plane), with $\mathrm{x}=0$ taken just in that surface. Figure 1 shows the linear variation of the potential difference across the rigid double layer formed between the electrode surface and $\mathrm{x}_{2}$, i. e., the distance at which the Outer Helmholtz Plane (OHP) is located. Once the electroactive substances are already situated at the OHP border, after reaching this position by diffusive transport, they can be supposed to behave like an ensemble of gas particles with respect to any infinitesimal approximation towards the electrode surface. In fact, the movement of the particles will still be by diffusion, but on distances as short as those considered, diffusion converts in a chaotic shift of the individual particles similar to the experimented by the molecules of a gas whose pressure diminishes when moving towards a wall. Therefore, the particles composing the electroactive substances, once they are situated in the OHP carry out a pulsing movement that allow them to repeatedly invade the double layer, where due to their electric charges and to the electric field acting in that region, a change in the values of the free energies of the redox couple takes place, which is proportional to the deep of their penetration inside the interphase.

The term $\exp \left(-\frac{\Delta G^{*}}{R T}\right)$, where $\Delta G^{*}=\frac{\lambda}{4}$, and $\lambda=$ energy of reorganization of the solvation shell, expresses the probability of reaching the situation of the activated complex, i.e., of creating electronic levels in the electroactive substances, able to accept or to transfer electrons from or towards electronic levels of the same energy in the electrode and can be calculated, according to the Marcus expression [7] as $\lambda / 4$, where $\lambda$ represents the reorganization energy of the solvation shell of the electroactive substance. 


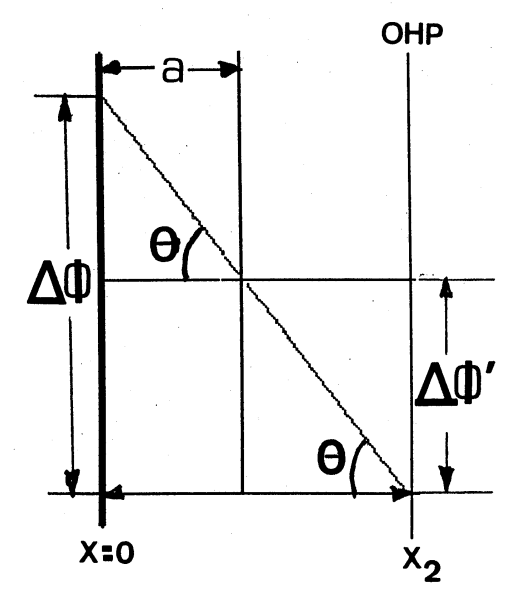

Figure 1. A representation of the rigid double layer. The vertical line at the left shows the cut of the electrode surface, whereas the vertical line at right at a distance $\mathrm{x}_{2}$ from the electrode surface is the cut of the Outer Helmholtz Plane (OHP). The distance a to the surface is the critical point that the electroactive substances must reach in order to make possible the tunnelling of electrons from or towards the electrode. In addition to reach this position, the electron tunnelling, from or towards the electrode, would take place whenever the solvation shell would adequately reorganise to allow the electron to find free levels in the electroactive substance or to permit electrons belonging to it to reach unoccupied levels of the same energy in the electrode. From the plot, it can be seen that: $\tan \vartheta=\frac{\Delta \Phi}{x_{2}}=\frac{\Delta \Phi^{\prime}}{\mathrm{x}_{2}-\mathrm{a}}$, and, consequently: $\Delta \Phi^{\prime}=\left(1-\frac{\mathrm{a}}{\mathrm{x}_{2}}\right) \Delta \Phi$.

These levels will be produced as consequence of thermal fluctuations in the solvation shells. The thermal fluctuations in the solvation shells are supposed in the present approach not to be influenced by the distance of penetration of the electroactive substances inside the double layer region since the thermal fluctuations in the solvation shell should be a function of the electric charge, the chemical nature of the electroactive substance and the temperature and these magnitudes will not be changed when the electroactive center is inside the interphasial region. Thus, the matching of the electronic energy levels in the redox system with the electronic levels in the electrode, which is necessary in order to induce a no-radiative electron transfer, is accomplished both, by the fluctuations in the solvation shell and as consequence of the linear variation of the electric field inside the double layer region. On the other hand, since the components of the redox couple (or, at least one of them) are electrically charged, they will interact with the electric field existing in the interphasial region (which varies linearly along it) with the result that their free energies will linearly vary in an amount expressed by: $\Delta \mathrm{G}=\mathrm{zF} \Delta \varphi$, where $\mathrm{z}$ is the electrical charge (or oxidation number) of the electroactive substance, $F$ the Faraday constant and $\Delta \varphi$ the absolute potential difference between the electrode surface and the point inside the double layer in which the charge transfer takes place. Once the charge transfer has taken place the oxidation number of the 
electroactive substance will change in \pm 1 and, consequently its free energy will proportionally change according to the deep of penetration of the electroactive substance inside the double layer. Thus, introducing the term: $\mathrm{z} F \Delta \varphi=\left(\mathrm{z}_{\mathrm{Ox}}-\right.$ $\left.\mathrm{Z}_{\text {Red }}\right) \mathrm{F} \Delta \varphi=\Delta \mathrm{G}_{\text {Red }}-\Delta \mathrm{G}_{\mathrm{Ox}}=\Delta(\Delta \mathrm{G})=\mathrm{f}(\Delta \varphi)$ is the form in which the energetic of the molecular redox levels is taken into account in the present approach. The complete treatment of the problem should also consider the populated and free electronic levels of the electrode around the Fermi level, which are those which are involved in charge transfer events. The partial solution of the problem for the potential range in which Butler-Volmer behaviour is found gives rise to the corresponding linear relation between the logarithm of the current and the potential, which is the mostly expected result in almost any experimental study made under the application of not extreme potentials, where, commonly parallel reactions like the own oxidation or reduction of the molecules component of the solvent or of the ions forming part of the supporting electrolyte, take place. This term will be multiplied by the probability of reaching a point inside the double layer close enough to the electrode surface to make possible the electron tunnelling from or towards it (where the probability for electron tunnelling is contained in the transmission coefficient, $\kappa$, which is the unity for the so called adiabatic electron transfers, the only ones considered in this treatment). Once the electroactive substances are located at the adequate distance (a distance at which the energy of the molecular levels in the redox system equals the energy of the first free or occupied levels in the electrode, at $\mathrm{E}=\mathrm{E}^{0 \prime}$ ), the proportion of them in which electronic levels are created able to receive electrons of the same energy from the electrode, or to transfer electrons to vacant levels of the same energy in the electrode is expressed by the exponential of the activation energy already written. The activation energy can be estimated by following the treatment of Marcus on polarization fluctuations in the solvation shell of the electroactive substances.

Such a critical distance will be reached a number of times by time and surface unities, which for a substance situated in front of a wall (and behaving as a gas, after reaching the position in the OHP by a diffusion process) is calculated by means of the expression [22]:

$$
Z_{W}=\mathrm{N} \int_{0}^{\infty} \mathrm{v}_{\mathrm{x}} f\left(v_{x}\right) d x
$$

and using the Boltzmann equation for the velocity distribution [22] in the direction $\mathrm{x}$ :

$$
f\left(v_{x}\right)=\left(\frac{\mathrm{m}}{2 \pi \mathrm{k}_{\mathrm{B}} \mathrm{T}}\right)^{1 / 2} \exp \left(-\frac{m v_{x}^{2}}{2 k_{B} T}\right) \mathrm{dv}_{\mathrm{x}}
$$

the resulting equation can be solved to give an expression for $\mathrm{Z}$ showing the correct dimensions, $\mathrm{cms}^{-1},\left(\frac{k_{B} T}{2 \pi \mathrm{m}}\right)^{1 / 2}$, (where $\mathrm{k}_{\mathrm{B}}$ represents the Boltzmann 
constant, $\mathrm{T}$, the absolute temperature and $\mathrm{m}$ the mass of the particle concerned). This is the expression for the frequency factor for the electrode reaction first derived by Hush and Evans [10] and from which a maximum value for the charge transfer rate constant of around $10^{4} \mathrm{cms}^{-1}$ (for $\Delta \mathrm{G}^{*}=0$ ) can be estimated (with changes associated to the change of value of $\mathrm{m}=$ molecular mass/number of Avogrado).

\section{The energetic of the molecular redox levels and of the electronic levels in the electrode}

In order to make possible the charge transfers towards or from the electrode the electroactive substances must come close enough to the electrode surface to make electron tunneling possible. This means that the electroactive substances will move in a perpendicular direction to the electrode surface, which is labeled with $\mathrm{x}$. By taking into account that the component in the direction $\mathrm{x}$ of the kinetic energy of a particle of mass $m$ can be written as: $E_{c}=\frac{1}{2} m v_{x}^{2}$, Equation (8) adopts the following form:

$$
f\left(v_{x}\right)=\left(\frac{\mathrm{m}}{2 \pi \mathrm{k}_{\mathrm{B}} \mathrm{T}}\right)^{1 / 2} \exp \left(-\frac{\mathrm{E}_{\mathrm{c}}}{\mathrm{k}_{\mathrm{B}} \mathrm{T}}\right)
$$

An analogous equation can be written for a particle component of an electroactive substance, located at the distance $\mathrm{x}_{2}$, i. e., at the OHP, from the electrode surface and moving to it, invading in this way, the interfacial region where an electric field is acting, whose strength is a linear function (for the rigid double layer model admitted to be valid in this case) of the depth of penetration of that particle. In that case, the distribution of velocities would be influenced by the presence of an electric field, i.e., the total energy would present an electric component $\left(\mathrm{E}_{\mathrm{el}}\right)$ which will be proportional to the charges of the electroactive substances involved, i. e., to the oxidation numbers $z_{O x}$ and $z_{\text {Red }}$ times $e_{0}$. This electric energy is proportional to the electric charge of the particle entering the double layer region and to the value of the electric field strength in the point reached by the particle. In the case that the particle considered would be electrically neutral, but bonded to another atom, the electrical charges will separate once it invades the interphasial zone. The electric field varies with the electrode potential and so do also the values of $\Delta \mathrm{G}_{\mathrm{Red}}$ and $\Delta \mathrm{G}_{\mathrm{Ox}}$, which will change with the electrode potential and with the position the redox components reach inside the double layer. Thus, considering the electrical energy of Ox and Red in the classical statistical mechanics approach is equivalent to introduce the potential dependent precursor and successor energies in the charge transfer processes. Under the influence of this new energy component, the velocity distribution would change. The expression for the new distribution, with $\mathrm{E}_{\text {total }}=$ $\mathrm{E}_{\mathrm{cx}}+\mathrm{E}_{\mathrm{elx}}$, (where $\mathrm{E}_{\mathrm{cx}}=$ component along $\mathrm{x}$ of the kinetic energy of the particles of the electroactive substance and $\mathrm{E}_{\mathrm{elx}}=$ component along $\mathrm{x}$ of the electric energy) can be written by taking into account that if the energy is a sum of 
independent contributions, the partition function is the product of the partition functions of each energy form ${ }^{[22]}$. Thus:

$$
\begin{gathered}
f\left(v_{x}, \mathrm{E}_{\mathrm{el}_{\mathrm{x}}}\right)=\left(\frac{\mathrm{m}}{2 \pi \mathrm{k}_{\mathrm{B}} \mathrm{T}}\right)^{1 / 2} \exp \left(-\frac{\mathrm{E}_{\text {total }}}{\mathrm{k}_{\mathrm{B}} \mathrm{T}}\right) \\
\left(\frac{\mathrm{m}}{2 \pi \mathrm{k}_{\mathrm{B}} \mathrm{T}}\right)^{1 / 2} \exp \left(-\frac{\mathrm{E}_{\mathrm{c}}}{\mathrm{k}_{\mathrm{B}} \mathrm{T}}\right) \exp \left(-\frac{\mathrm{E}_{\mathrm{el}}}{\mathrm{k}_{\mathrm{B}} \mathrm{T}}\right) \mathrm{dE}_{\mathrm{el}} \mathrm{dE}_{\mathrm{c}}
\end{gathered}
$$

The expression for the electric contribution to the probability can be deduced as follows:

The Boltzmann distribution is defined as the fraction of molecules, $\mathrm{p}_{\mathrm{i}}$, from an ensemble $\mathrm{N}$, existing in the state $\mathrm{i}$ :

$$
p_{i}=\frac{\mathrm{n}_{\mathrm{i}}}{\mathrm{N}}=\frac{\exp \left(-\frac{\varepsilon_{\mathrm{i}}}{\mathrm{k}_{\mathrm{B}} T}\right)}{q}
$$

where $q$ represents the molecular partition function. It is necessary to remember that the molecular partition function carries all the thermodynamic information about a system, so that the energetic conditions corresponding to the precursor and successor states in the charge transfer reaction will become a result of the mechanical statistical treatment [22]. For the case of a charged particle, which, as consequence of thermal fluctuations can reach different positions inside the double layer region, the partition function can be admitted to coincide with that calculated for a situation in which a molecule can occupy an infinite number of equally spaced non-degenerate energy levels, coinciding with any infinitesimal variation of the "penetration" of the charged particle inside the double layer, $i$. e.,:

$$
q=\frac{1}{1-\exp \left(-\frac{\varepsilon_{i}}{k_{B} T}\right)}
$$

and the Boltzmann distribution can, therefore, be written as follows:

$$
p_{i}=\exp \left(-\frac{\varepsilon_{i}}{k_{B} T}\right)\left(1-\exp \left(-\frac{\varepsilon_{i}}{k_{B} T}\right)\right)
$$

or, for $\varepsilon i<<k_{B} T$,

$$
p_{i}=\frac{\varepsilon_{\mathrm{i}}}{\mathrm{k}_{\mathrm{B}} T} \exp \left(-\frac{\varepsilon_{i}}{k_{B} T}\right)
$$


Making $\varepsilon_{\mathrm{i}}=\mathrm{ze}_{0} \mathrm{dE}=\mathrm{E}_{\mathrm{el}}$, Eq. 15, converts in $\mathrm{p}_{\mathrm{i}}=\mathrm{p}_{\mathrm{el}}=\frac{z e_{0}}{k_{B} T} \exp \left(-\frac{E_{e l}}{k_{B} T}\right) \mathrm{dE}$, which represents the contribution to the energy distribution made by the electric energy, as included in Eq. 11.

On the other hand, when the total energy of a molecule arises from the sum of several different, independent sources (in this case, thermal fluctuations plus electric interaction of the electroactive particle "invading" the interfacial region with the electric field acting inside it), the total partition function is a product of the partition functions for each energetic mode. Thus, $p_{\text {total }}=p_{\text {thermal }} \times p_{\text {electric }}$, with $\varepsilon_{\mathrm{el}}=-\mathrm{ze}_{0} \Delta \varphi$, where $\Delta \varphi$ represents the Galvani's potential difference across the double layer. Since the real magnitude we are able to measure is $\Delta \varphi+E^{*}$, where $\mathrm{E}^{*}$ represents the unknown absolute or Galvani's potential difference across the interface chosen as reference then we will write the electric potential difference as a function of $\mathrm{E}$ instead of $\Delta \varphi$. In this way Eq. (11) becomes justified.

\section{The frequency factor for the oxidation process}

With Eq. (11) as the expression for the new distribution, the frequency factor, i.e., the number of times by time and surface units, in which the charged particle is able to reach a point in the double layer where the tunneling of electrons will be effective whenever adequate energetic levels for the electron exist, must be written by taking into account the effective density of electronic states, $\rho_{M}(\varepsilon)$ (where $\varepsilon=\mathrm{E}-\mathrm{E}_{\mathrm{F}}$ ), near the Fermi level $\left(\mathrm{E}_{\mathrm{F}}\right)$, which is assumed to be independent of the energy. In addition to this, it must be taken also into account the probability of finding in the electrode an occupied electronic state of energy $\varepsilon$ with respect to $\mathrm{E}_{\mathrm{F}}$ when studying a reduction process, or free electronic levels of energy $-\varepsilon$ in the electrode for the oxidation process. Such probabilities are given by the products: $\rho_{M}\left(E_{F}\right) f(\varepsilon)$ and $\rho_{M}\left(E_{F}\right)[1-f(\varepsilon)]$ respectively, where:

$$
f(\varepsilon)=\frac{1}{1+\exp \left[\frac{\varepsilon}{\mathrm{k}_{\mathrm{B}} \mathrm{T}}\right]}
$$

For the case of an oxidation process, an electron occupying the HOMO (Highest Occupied Molecular Orbital) of Red can only be transferred to the electrode if an empty state of the same energy is available in it. The probability of finding such an empty state is given by: $\rho_{M}(\varepsilon)[1-f(\varepsilon)]$. Therefore, the frequency factor for an oxidation process taking place under adiabatic conditions $(\kappa=1)$ can be written as follows:

$$
\begin{aligned}
& Z=-\int_{0}^{\infty} \mathrm{v}_{\mathrm{x}}\left(\frac{m}{2 \pi \mathrm{k}_{\mathrm{B}} \mathrm{T}}\right)^{1 / 2} \exp \left(-\frac{\mathrm{mv}_{\mathrm{x}}^{2}}{2 \mathrm{k}_{\mathrm{B}} \mathrm{T}}\right) \mathrm{dv_{ \textrm {x } }} \int_{\left(1-\frac{\mathrm{a}}{\mathrm{x}_{2}}\right)}^{-\infty}\left[\Delta(\Delta \varphi)-\frac{\varepsilon}{z e_{0}}\right] \exp \left(\frac{\mathrm{ze}_{0} \Delta(\Delta \varphi)}{\mathrm{k}_{\mathrm{B}} \mathrm{T}}\right) \frac{\mathrm{ze}_{0}}{\mathrm{k}_{\mathrm{B}} T} d(\Delta \varphi) x \\
& \int_{-\infty}^{+\infty} \rho_{M}(\varepsilon)[1-f(\varepsilon)] d \varepsilon
\end{aligned}
$$


where, it has been substituted, for an oxidation process: $\mathrm{E}_{\mathrm{el}}=-\mathrm{ze}_{0} \Delta(\Delta \varphi)$ and $\mathrm{dE}_{\mathrm{el}}$ $=-\mathrm{z} \mathrm{e} \mathrm{e}_{0} \mathrm{~d}(\Delta \varphi)$

The integration limits are 0 and $+\infty$ for the integral of the kinetic component, since only the movement in the positive direction along $\mathrm{x}$ of the particles approximates them to the double layer. Likewise, the integration limits for the integral on the electric energy component $\operatorname{are}\left(1-\frac{a}{x_{2}}\right)\left[\Delta(\Delta \varphi)-\frac{\varepsilon}{z e_{0}}\right]$ and $-\infty$, where the fraction $-\frac{\varepsilon}{z e_{0}}$ indicates the energetic levels above the Fermi level which can accept electrons from the reduced substance in the electrolyte, but expressed in potential unities and $\varepsilon=E-E_{F}$, with $E_{F}=$ Fermi level. The limit $-\infty$ implies a situation in which the difference in energy between the occupied levels in Red and the unoccupied levels in the electrode is as high that no charge transfer event can take place from Red to the electrode, since every level in it is occupied. The integration limit $\left(1-\frac{a}{x_{2}}\right)\left[\Delta(\Delta \varphi)-\frac{\varepsilon}{z e_{0}}\right]$ accounts for all the values of $\Delta \varphi$ and a in which the levels around the Fermi level in the electrode and the energy levels in the redox couple are of the same energy, allowing no radiative electron transfers to each other. Since the initial situation in the process is that created at the formal potential, then $\Delta(\Delta \varphi)=\Delta \varphi-\Delta \varphi_{\mathrm{e}}=\mathrm{E}-\mathrm{E}^{0^{\prime}}$, where $\Delta \varphi_{\mathrm{e}}$ and $\mathrm{E}^{0^{\prime}}$ are the absolute or Galvani's equilibrium potential difference across the double layer and the measured formal potential and the applied potential, respectively. The kinetic equations will be written as a function of the concentrations of the electroactive substances instead of their activities, thus the difference which should be considered is: $\mathrm{E}-\mathrm{E}^{0}$, where $\mathrm{E}^{0}$, denotes the formal potential and $\mathrm{E}$ the applied potential. Thus:

$$
\left(1-\frac{\mathrm{a}}{\mathrm{x}_{2}}\right) \Delta(\Delta \varphi)=\left(1-\frac{a}{x_{2}}\right)\left[E-\mathrm{E}^{0^{\prime}}\right]
$$

where the product of $\left[\mathrm{E}-\mathrm{E}^{0}\right] \mathrm{e}_{0}$ expresses the driving force for the electron transfer from Red towards the electrode.

Making the frequency factor the product of the integrals I, J and K:

$\mathrm{Z}=\mathrm{IxJxK}$

with

$$
\begin{aligned}
I=\int_{0}^{\infty} \mathrm{v}_{\mathrm{x}}\left(\frac{m}{2 \pi \mathrm{k}_{\mathrm{B}} \mathrm{T}}\right)^{1 / 2} & \exp \left(-\frac{\mathrm{mv}_{\mathrm{x}}^{2}}{2 \mathrm{k}_{\mathrm{B}} \mathrm{T}}\right) \mathrm{d}^{\mathrm{v}_{\mathrm{x}}}= \\
& =\left(\frac{m}{2 \pi k_{B} T}\right)^{1 / 2} \int_{0}^{\infty} v_{x} \exp \left(-\frac{m v_{x}^{2}}{2 k_{B} T}\right) d v_{x}
\end{aligned}
$$

This integral can be solved by resorting to following change of variable: 


$$
\mathrm{x}^{2}=\frac{\mathrm{mv}_{\mathrm{x}}^{2}}{\mathrm{k}_{\mathrm{B}} \mathrm{T}} ; \mathrm{v}_{\mathrm{x}}^{2}=\frac{2 \mathrm{k}_{\mathrm{B}} \mathrm{T} \mathrm{x}^{2}}{\mathrm{~m}} ; 2 \mathrm{v}_{\mathrm{x}} \mathrm{dv}_{\mathrm{x}}=\frac{4 \mathrm{k}_{\mathrm{B}} \mathrm{T} \mathrm{x}}{\mathrm{m}} \mathrm{dx}
$$

Now, the integral I can be written in the following way:

$$
I=\left(\frac{m}{2 \pi k_{B} T}\right)^{1 / 2}\left(\frac{2 k_{B} T}{m}\right) \int_{0}^{\infty} x \exp \left(-x^{2}\right) d x
$$

where the integral is tabulated: $\int_{0}^{\infty} x^{n} \exp \left(-a x^{2}\right) d x$, and, for $n=1$, the solution is: $\frac{1}{2 \mathrm{a}}$, and for $\mathrm{a}=1$, the solution is $1 / 2$. Thus:

$$
I=\left(\frac{m}{2 \pi k_{B} T}\right)^{1 / 2}\left(\frac{2 k_{B} T}{m}\right) \frac{1}{2}=\left(\frac{k_{B} T}{2 \pi m}\right)^{1 / 2}
$$

The integral $\mathrm{J}$ can be solved in the following way:

$$
\begin{gathered}
J=-\int_{\left(1-\frac{\mathrm{a}}{\mathrm{x}_{2}}\right)}^{-\infty}\left[\left(E-E^{0^{\prime}}\right)-\frac{\varepsilon}{z e_{0}}\right] \exp \left(\frac{\mathrm{ze}_{0} \Delta \varphi}{\mathrm{k}_{\mathrm{B}} \mathrm{T}}\right)\left[\frac{\mathrm{ze}_{0}}{k_{B} T}\right] \mathrm{d} \Delta \varphi= \\
=\mathrm{J}=-\int_{\left(1-\frac{\mathrm{a}}{\mathrm{x}_{2}}\right)\left[\left(E-E^{0^{\prime}}\right)-\frac{\varepsilon}{z e_{0}}\right] d\left(\exp \left(\frac{z \mathrm{e}_{0} \Delta \varphi}{\mathrm{k}_{\mathrm{B}} T}\right)\right)}^{-\infty}\left(\frac{\mathrm{ze}_{0}\left(1-\frac{\mathrm{a}}{\mathrm{x}_{2}}\right)\left(E-E^{0^{\prime}}\right)}{\mathrm{k}_{\mathrm{B}} \mathrm{T}}\right) \exp \left(-\frac{\left(1-\frac{\mathrm{a}}{\mathrm{x}_{2}}\right) \varepsilon}{\mathrm{k}_{\mathrm{B}} \mathrm{T}}\right)
\end{gathered}
$$

where the second exponential factor depends on $\varepsilon$ and, therefore it must be included in the integral $\mathrm{K}$.

In establishing the integration limits for the integral with respect to the electrical part of the partition function an introduction is made of the energy of the molecular redox levels and of the populated and empty electronic levels around the Fermi level in the electrode and therefore establishing the energetic conditions under which interphasial charge transfer can take place. Again, $\left(1-\frac{\mathrm{a}}{\mathrm{x}_{2}}\right)\left(E-E^{0^{\prime}}\right)$, is the fraction of the total absolute potential difference acting at the critical distance, a, which the electroactive substance must penetrate in the interphasial region in order for the electron tunnelling to become possible, i. e., in order to reach the situation in which occupied electronic levels in the reduced substance reach an energy equal to the energy of the free electronic levels in the electrode. In this way, a non radiative electron transfer can take 
place from the occupied molecular orbitals of Red towards unoccupied electronic levels of the same energy in the electrode. $z$, represents the difference in the oxidation numbers of the Redox couple, i.e., $\mathrm{z}=\mathrm{z}_{\mathrm{O}}-\mathrm{z}_{\mathrm{R}}$ normally would be equal to 1 (or, more generally, $\mathrm{n}_{\beta}$ ) since the probability for two electrons to simultaneously tunnel is extremely small.

The solution of the integral $\mathrm{K}$ can be obtained in the following way;

$$
\mathrm{K}=\int_{-\infty}^{+\infty}[1-\mathrm{f}(\varepsilon)] \rho_{\mathrm{M}}(\varepsilon) \exp \left(-\frac{\left(1-\frac{\mathrm{a}}{\mathrm{x}_{2}}\right) \varepsilon}{\mathrm{k}_{\mathrm{B}} \mathrm{T}}\right) \mathrm{d} \varepsilon=
$$

The integration limits are $+\infty$ and $-\infty$ because the integral has to be performed over the conduction band of the metal and the integrands become negligible far from the Fermi level.

$$
=\int_{-\infty}^{+\infty} \frac{\exp \left(\frac{\varepsilon}{\mathrm{k}_{\mathrm{B}} T}\right)}{1+\exp \left(\frac{\varepsilon}{\mathrm{k}_{\mathrm{B}} T}\right)} \rho_{\mathrm{M}}(\varepsilon) \exp \left(-\frac{\left(1-\frac{\mathrm{a}}{\mathrm{x}_{2}}\right) \varepsilon}{\mathrm{k}_{\mathrm{B}} \mathrm{T}}\right) \mathrm{d} \varepsilon=
$$

On the other hand, the density of states, $\rho_{M}(\varepsilon)$ varies slowly near the Fermi level, and, in consequence, it can be taken as constant, $\rho_{M}\left(E_{F}\right)$, and put in the front of the integration sign:

$$
\begin{gathered}
=\rho_{M}\left(E_{F}\right) \int_{-\infty}^{+\infty} \frac{\exp \left(\frac{\varepsilon}{\mathrm{k}_{\mathrm{B}} T}-\frac{\left(1-\frac{\mathrm{a}}{\mathrm{x}_{2}}\right)}{k_{B} T}\right)}{1+\exp \left(\frac{\varepsilon}{\mathrm{k}_{\mathrm{B}} T}\right)} d \varepsilon= \\
=\rho_{\mathrm{M}}\left(\mathrm{E}_{\mathrm{F}}\right) \int_{-\infty}^{+\infty} \frac{\exp \left(\frac{\mathrm{a} \varepsilon}{\mathrm{x}_{2} \mathrm{k}_{\mathrm{B}} \mathrm{T}}\right)}{1+\exp \left(\frac{\varepsilon}{\mathrm{k}_{\mathrm{B}} \mathrm{T}}\right)} \mathrm{d} \varepsilon
\end{gathered}
$$

and making the change of variable: $x=\frac{\varepsilon}{\mathrm{k}_{\mathrm{B}} \mathrm{T}} ; \mathrm{d} \varepsilon=\left(\mathrm{k}_{\mathrm{B}} \mathrm{T}\right) \mathrm{dx}$, and substituting:

$$
K=\rho\left(\mathrm{E}_{\mathrm{F}}\right)\left(k_{B} T\right)\left(\int_{-\infty}^{+\infty} \frac{\exp \left(\frac{a}{\mathrm{x}_{2}} x\right)}{1+\exp (\mathrm{x})} d x\right)
$$


The integral between the brackets can be solved for the most common case, i. e., for $\beta=\frac{a}{x_{2}}=0.5$. In that case, dividing numerator and denominator in the integrand by $\exp \left(\frac{\mathrm{a}}{\mathrm{x}_{2}} \mathrm{x}\right)$ :

$$
K=\rho\left(\mathrm{E}_{\mathrm{F}}\right)\left(k_{B} T\right)\left(\int_{-\infty}^{+\infty} \frac{1}{\exp \left(-\frac{\mathrm{x}}{2}\right)+\exp \left(\frac{\mathrm{x}}{2}\right)} d x\right)
$$

The integral in the brackets is tabulated with the solution: $\left[2 \operatorname{arctg}\left(e^{x / 2}\right)\right]$, and, therefore:

$$
\begin{gathered}
\mathrm{K}=\rho\left(\mathrm{E}_{\mathrm{F}}\right)\left(\mathrm{k}_{\mathrm{B}} \mathrm{T}\right)\left[2 \operatorname{arctg}\left(e^{x / 2}\right)\right]_{-\infty}^{+\infty}=\rho\left(\mathrm{E}_{\mathrm{F}}\right)\left(\mathrm{k}_{\mathrm{B}} \mathrm{T}\right)\left[2 \frac{\pi}{2}-0\right]= \\
=\pi \rho\left(\mathrm{E}_{\mathrm{F}}\right)\left(\mathrm{k}_{\mathrm{B}} \mathrm{T}\right)=\mathrm{K}
\end{gathered}
$$

The general solution for Eq. 29 is given in Appendix 1. Thus, making a/ $x_{2}=\beta$, the resulting integral: $\int_{-\infty}^{+\infty} \frac{e^{\beta x}}{1+\mathrm{e}^{\mathrm{x}}} d x$ for $0 \leq \beta \leq 1$, has the solution: $\frac{\pi}{\sin \beta \pi}$ and, therefore, the general solution for $\mathrm{K}$ is:

$$
K=\rho\left(\mathrm{E}_{\mathrm{F}}\right)\left(k_{B} T\right) \int_{-\infty}^{+\infty} \frac{e^{\beta x}}{1+\mathrm{e}^{\mathrm{x}}} \mathrm{dx}=\rho\left(\mathrm{E}_{\mathrm{F}}\right)\left(k_{B} T\right) \frac{\pi}{\sin \beta \pi}
$$

For $\beta=1 / 2, \sin \beta \pi=\sin \pi / 2=1, \frac{\pi}{\sin \beta \pi}=\pi$, and the solution coincides with the value of $\mathrm{K}$ given in Eq. 31. On the other hand, for values of $\beta=0.1,0.2,0.3,0.4$, $0.6,0.7,0.8,0.9$, the fraction $\frac{\pi}{\sin \beta \pi}$, will present the values: $3.24 \pi, 1.7 \pi, 1.24 \pi$, $1.05 \pi, 1.05 \pi, 1.24 \pi, 1.7 \pi$ and $3.24 \pi$, respectively. In general, the result is that the frequency factor shows a double dependency on the symmetry factor, $\beta$, one linear an another exponential. According to this result, the frequency factor and, therefore, the rate constant will reach higher values the closer to 0 or to $1 \beta$ is. Finally, the frequency factor can be obtained according to:

$$
\mathrm{Z}_{\mathrm{OX}}(\mathrm{E})=\mathrm{IxJxK}=\frac{\pi}{\sin \beta \pi} \rho\left(\mathrm{E}_{\mathrm{F}}\right)\left(\mathrm{k}_{\mathrm{B}} \mathrm{T}\right)\left(\frac{\mathrm{k}_{\mathrm{B}} \mathrm{T}}{2 \pi \mathrm{m}}\right)^{1 / 2} \exp \left(\frac{\mathrm{ze}\left(1-\frac{\mathrm{a}}{\mathrm{x}_{2}}\right)\left(E-E^{0^{\prime}}\right)}{k_{B} T}\right)
$$

where: $\frac{\mathrm{a}}{\mathrm{x}_{2}}=\beta$ and, according to Fig. $1: 0 \leq \beta \leq 1$

The so called symmetry factor, $\beta$, is now an dimensionless coefficient, which expresses the fraction of the whole width of the interphasial region, into which 
the electroactive substances must enter, in order to make possible the electron transfers. On the other hand, this factor combines with the probability factor expressed by: $\exp \left(-\Delta \mathrm{G}^{*} / \mathrm{RT}\right)$ to give the total frequency of the charge transfers, or, more adequately expressed, the charge transfer specific rate. Again, since a $<$ $\mathrm{x}_{2}$, it results that: $0 \leq \beta \leq 1$.

Substituting now Eq. (32) in Eq. (6), the expression for the rate constant for the oxidation of $\mathrm{R}$, and remembering that for the oxidation process, $\mathrm{z}=\mathrm{z}_{\mathrm{O}}-\mathrm{z}_{\mathrm{R}}=\mathrm{n}_{\beta}$ $\left(\mathrm{n}_{\beta}=\right.$ number of electrons simultaneously transferred) becomes:

$$
k(E)_{O x}=\kappa \frac{\pi}{\sin \beta \pi} \rho_{\mathrm{M}}\left(E_{F}\right)\left(\frac{\mathrm{k}_{\mathrm{B}} \mathrm{T}}{2 \pi \mathrm{m}}\right)^{1 / 2}\left(k_{B} T\right) \exp \left(-\frac{\Delta \mathrm{G}_{O x}^{*}}{\mathrm{RT}}\right) \exp \left(\frac{\mathrm{n}_{\beta} \mathrm{e}_{0}(1-\beta)\left(E-E^{0^{\prime}}\right)}{\mathrm{k}_{\mathrm{B}} \mathrm{T}}\right)
$$

\section{The frequency factor for the reduction process}

In a similar way, the value of the rate constant for the reduction process must take into account the probability of finding electrons in the electrode with the same energy as the molecular free levels in Ox, which is expressed by: $\rho_{M}(\varepsilon)$. Thus:

$$
k(\Delta \varphi)_{\mathrm{Re} d}=\kappa \mathrm{Z}_{\mathrm{Red}}(\Delta \varphi) \exp \left(-\frac{\Delta \mathrm{G}_{\mathrm{Red}}^{*}}{\mathrm{RT}}\right)
$$

and the term $\mathrm{Z}_{\operatorname{Red}}(\mathrm{E})$ is given by:

$$
Z_{\mathrm{Re} d}(E)=\left(\frac{\mathrm{k}_{\mathrm{B}} \mathrm{T}}{2 \pi \mathrm{m}}\right)^{1 / 2} \int\left[\frac{\mathrm{a}}{\mathrm{x}_{2}}\left[\left(E-E^{0^{\circ}}\right)-\frac{\varepsilon}{z e_{0}}\right]\right] \exp \left(-\frac{\mathrm{z}_{0} \Delta \varphi}{\mathrm{k}_{\mathrm{B}} \mathrm{T}}\right) \mathrm{d} \Delta \varphi\left(\frac{z e_{0}}{k_{B} T}\right) \int_{-\infty}^{+\infty} \rho_{M}(\varepsilon) \mathrm{f}(\varepsilon) \mathrm{d} \varepsilon
$$

where for a reduction process $\mathrm{E}_{\mathrm{el}}=\mathrm{ze}_{0} \Delta \varphi$. The limit $+\infty$ for the value of the potential describes a situation in which the electronic levels in the electrode are unoccupied and, therefore, no electron transfer will be possible from it to the electroactive substance Ox, at any distance it could be located inside the double layer, whereas $-\varepsilon / \mathrm{ze}_{0}$ represents the levels of electrons in the metal more energetic than $\mathrm{E}_{\mathrm{F}}$ from which electrons can be transferred to Ox in the electrolyte to form Red.

Thus, $Z_{\text {Red }}=\mathrm{IxJ}^{\prime} \mathrm{xK} \mathrm{K}^{\prime}$

The integrals, J'x K', in Eq. (26) can be solved following the same steps as before:

$$
\begin{aligned}
& \left.\mathrm{J}^{\prime}=\int_{\left[\frac{\mathrm{a}}{\mathrm{x}_{2}}\left[\left(E-E^{0^{\prime}}\right)-\frac{\varepsilon}{z e_{0}}\right]\right.}^{+\infty}\right] \exp \left(-\frac{\mathrm{z}_{0} \Delta \varphi}{\mathrm{k}_{\mathrm{B}} \mathrm{T}}\right) \mathrm{d} \Delta \varphi\left(\frac{z e_{0}}{k_{B} T}\right)= \\
& =-\int_{\left[\frac{\mathrm{a}}{\mathrm{x}_{2}}\left[\left(E-E^{0^{\prime}}\right)-\frac{\varepsilon}{z e_{0}}\right]\right.}^{+\infty} \mathrm{d}\left(\exp \left(-\frac{\mathrm{ze}_{0} \Delta \varphi}{k_{B} T}\right)\right)=
\end{aligned}
$$




$$
=\exp \left[\frac{-e_{0}\left(\frac{a}{x_{2}}\right)\left[\left(E-\mathrm{E}^{0^{\prime}}\right)-\frac{\varepsilon}{\mathrm{ze}_{0}}\right]}{\mathrm{k}_{\mathrm{B}} T}\right]=
$$

and remembering that $\mathrm{z}=\mathrm{n}_{\beta}$

$$
=\exp \left[-\frac{\mathrm{n}_{\beta} e_{0}\left(\frac{a}{x_{2}}\right)\left[\left(E-\mathrm{E}^{0^{\prime}}\right)\right]}{\mathrm{k}_{\mathrm{B}} T}\right] \exp \left[\frac{\mathrm{a} \varepsilon}{\mathrm{x}_{2} k_{B} T}\right]
$$

where the second exponential is a function of $\varepsilon$ and, therefore, it must be included in the calculation of $\mathrm{K}^{\prime}$.

Thus:

and:

$$
\mathrm{J}^{\prime}=\exp \left[-\frac{\mathrm{n}_{\beta} e_{0}\left(\frac{a}{x_{2}}\right)\left[\left(E-\mathrm{E}^{0^{\prime}}\right)\right]}{\mathrm{k}_{\mathrm{B}} T}\right]
$$

$$
\begin{gathered}
K^{\prime}=\rho_{\mathrm{M}}\left(E_{F}\right) \int_{-\infty}^{+\infty} f(\varepsilon) \exp \left(\frac{\mathrm{a} \varepsilon}{\mathrm{x}_{2} k_{B} T}\right) d \varepsilon= \\
=K^{\prime}=\rho_{\mathrm{M}}\left(E_{F}\right) \int_{-\infty}^{+\infty} \frac{1}{1+\exp \left(\frac{\varepsilon}{\mathrm{k}_{\mathrm{B}} T}\right)} \exp \left(\frac{\mathrm{a} \varepsilon}{\mathrm{x}_{2} k_{B} T}\right) d \varepsilon
\end{gathered}
$$

Eq. (43) is the same as Eq. (28), and, therefore, its solution (Appendix 1) is:

$$
\mathrm{K}^{\prime}=\frac{\pi}{\sin \beta \pi}\left(\mathrm{k}_{\mathrm{B}} \mathrm{T}\right) \rho_{\mathrm{M}}\left(\mathrm{E}_{\mathrm{F}}\right)
$$

So that the expression for $Z_{\operatorname{Red}}(E)=I_{x J} x^{\prime} K^{\prime}=$

$$
\mathrm{Z}_{\mathrm{Red}}=\frac{\pi}{\sin \beta \pi} \rho_{\mathrm{M}}\left(E_{F}\right)\left(\mathrm{k}_{\mathrm{B}} \mathrm{T}\right)\left(\frac{\mathrm{k}_{\mathrm{B}} \mathrm{T}}{2 \pi \mathrm{m}}\right)^{1 / 2} \exp \left(-\frac{\mathrm{n}_{\beta} \mathrm{e}_{0} \beta\left(E-E^{0^{\prime}}\right)}{\mathrm{k}_{\mathrm{B}} \mathrm{T}}\right)
$$

or, substituting Eq. (45) in Eq. (35):

$$
k_{\mathrm{Re} d}(E)=\kappa \frac{\pi}{\sin \beta \pi} \rho_{\mathrm{M}}\left(E_{F}\right)\left(\mathrm{k}_{\mathrm{B}} \mathrm{T}\right)\left(\frac{\mathrm{k}_{\mathrm{B}} \mathrm{T}}{2 \pi \mathrm{m}}\right)^{1 / 2} \exp \left(-\frac{\Delta \mathrm{G}_{\mathrm{Red}}^{*}}{\mathrm{RT}}\right) \exp \left(-\frac{\mathrm{n}_{\beta} \mathrm{e}_{0} \beta\left(E-E^{0^{\prime}}\right)}{\mathrm{k}_{\mathrm{B}} \mathrm{T}}\right)
$$


By defining now the values of the rate constants at the formal potential, i. e., for $\mathrm{E}=\mathrm{E}^{0^{\prime}}$ :

$$
k_{O x}^{0}=\kappa \frac{\pi}{\sin \beta \pi} \rho_{\mathrm{M}}\left(E_{F}\right)\left(\mathrm{k}_{\mathrm{B}} \mathrm{T}\right)\left(\frac{\mathrm{k}_{\mathrm{B}} \mathrm{T}}{2 \pi \mathrm{m}}\right)^{1 / 2} \exp \left(-\frac{\Delta \mathrm{G}_{\mathrm{Ox}}^{*}}{\mathrm{RT}}\right)
$$

and:

$$
k_{\mathrm{Re} d}^{0}=\kappa \frac{\pi}{\sin \beta \pi} \rho_{M}\left(E_{F}\right)\left(\mathrm{k}_{\mathrm{B}} \mathrm{T}\right)\left(\frac{\mathrm{k}_{\mathrm{B}} \mathrm{T}}{2 \pi \mathrm{m}}\right)^{1 / 2} \exp \left(-\frac{\Delta \mathrm{G}_{\mathrm{Red}}^{*}}{\mathrm{RT}}\right)
$$

where $\kappa$ is dimensionless, $\rho_{M}(\varepsilon)$ is given in number of electronic levels/eV and the energy $k_{\mathrm{B}} \mathrm{T}$ can be expressed in $\mathrm{eV}$, so that the rate constant has the dimensions of the term $\left(\frac{\mathrm{k}_{\mathrm{B}} \mathrm{T}}{2 \pi \mathrm{m}}\right)^{1 / 2}$, i.e., $\mathrm{cms}^{-1}$, those, therefore, of a heterogeneous first order reaction. The expressions of $\mathrm{k}^{0}$ given in Eqs. (47) and (48) coincide with those deduced previously [4] starting from the Marcus-Hush formalism (where those expressions were derived only for $\beta=1 / 2$ ) but adding the presence of the factor $\left(\frac{\mathrm{k}_{\mathrm{B}} \mathrm{T}}{2 \pi \mathrm{m}}\right)^{1 / 2}$.

Eqs. (33) and (46) can now be written as follows:

$$
\mathrm{k}_{\mathrm{Ox}}(\mathrm{E})=\mathrm{k}_{\mathrm{Ox}}^{0} \exp \left(\frac{\mathrm{n}_{\beta} \mathrm{e}_{0}(1-\beta)\left(\mathrm{E}-\mathrm{E}^{0^{\prime}}\right)}{\mathrm{k}_{\mathrm{B}} \mathrm{T}}\right)
$$

and

$$
\mathrm{k}_{\operatorname{Red}}(\mathrm{E})=\mathrm{k}_{\mathrm{Red}}^{0} \exp \left(-\frac{\mathrm{n}_{\beta} \mathrm{e}_{0} \beta\left(\mathrm{E}-\mathrm{E}^{0^{\prime}}\right)}{\mathrm{k}_{\mathrm{B}} \mathrm{T}}\right)
$$

At $\mathrm{E}=\mathrm{E}^{0^{\prime}}$, for equal initial concentrations of $\mathrm{Ox}$ and Red, it results the so-called standard rate constant $\mathrm{k}^{0}$ :

$$
\begin{gathered}
k_{O x}^{0}=\kappa \frac{\pi}{\sin \beta \pi} \rho_{\mathrm{M}}\left(E_{F}\right)\left(\mathrm{k}_{\mathrm{B}} T\right)\left(\frac{\mathrm{k}_{\mathrm{B}} \mathrm{T}}{2 \pi \mathrm{m}}\right)^{1 / 2} \exp \left(-\frac{\Delta \mathrm{G}_{\mathrm{Ox}}^{*}}{\mathrm{RT}}\right)= \\
=k_{\mathrm{Re} d}^{0}=\kappa \frac{\pi}{\sin \beta \pi} \rho_{\mathrm{M}}\left(E_{F}\right)\left(\mathrm{k}_{\mathrm{B}} \mathrm{T}\right)\left(\frac{\mathrm{k}_{\mathrm{B}} \mathrm{T}}{2 \pi \mathrm{m}}\right)^{1 / 2} \exp \left(-\frac{\Delta \mathrm{G}_{\mathrm{Red}}^{*}}{\mathrm{RT}}\right)=\mathrm{k}^{0}
\end{gathered}
$$

and the frequency factors for $\mathrm{E}=\mathrm{E}^{0}$ ' would be:

$$
(Z)_{E^{0^{\prime}}}=\left(\mathrm{Z}_{\mathrm{Ox}}\right)_{E^{0^{\prime}}}=\left(\mathrm{Z}_{\mathrm{Red}}\right)_{E^{0^{\prime}}}=\kappa \frac{\pi}{\sin \beta \pi} \rho_{\mathrm{M}}\left(E_{F}\right)\left(\mathrm{k}_{\mathrm{B}} T\right)\left(\frac{\mathrm{k}_{\mathrm{B}} T}{2 \pi \mathrm{m}}\right)^{1 / 2}
$$


Thus, the frequency factor measured at the formal potential includes also a dependence on the symmetry factor, $\beta$. Equation 51a allows an estimation of $(Z)_{E^{\circ}}$ by taking into account values of $\rho_{\mathrm{M}}\left(E_{F}\right) \cong 0.3$ levels/eV (for instance, for a gold electrode), $\left(\mathrm{k}_{\mathrm{B}} T\right) \cong 0.0256 \mathrm{eV}$ at $298 \mathrm{~K}, \beta=1 / 2$, and, therefore, $\sin \beta \pi=\sin$ $\pi / 2=1$, and $\left(\frac{\mathrm{k}_{\mathrm{B}} T}{2 \pi \mathrm{m}}\right)^{1 / 2} \cong 5000 \mathrm{cms}^{-1}$ for ions derived from the first transition series, gives rise to a maximum value for $\mathrm{k}^{0}$ of around $200 \mathrm{cms}^{-1}\left(\right.$ for $\Delta \mathrm{G}^{*}=0$ ) and the same value multiplied by $3.24\left(648 \mathrm{cms}^{-1}\right)$ for values of $\beta=0.1$ and 0.9 . These equations for $\mathrm{k}^{0}$ deduced from the supposition that the frequency factor instead of the activation energy is potential dependent suppose a new definition for them and predict a double temperature dependence of $\mathrm{k}^{0}$, through the presence of the temperature in the exponential factor and through the factor $\mathrm{T}^{3 / 2}$. In addition to this, the preexponential factor is a function of the symmetry factor. Furthermore, Equations (51) allow to do a theoretical estimation of the values of $\mathrm{k}^{0}$ by taking into account calculations of $\Delta \mathrm{G}^{*}$ as $\lambda / 4$ and introducing the values of the effective density of electronic states near the Fermi level of the electrode, which is supposed to be independent of the energy, $\rho_{M}\left(E_{F}\right)$, the working temperature and the molecular mass of the electroactive substance $\mathrm{m}$.

\section{Current-potential characteristic for a redox process}

A substitution of the expressions (51) in Eqs. (33) and (46) leads to:

$$
\mathrm{k}_{\mathrm{Ox}}(\mathrm{E})=\mathrm{k}^{0} \exp \left(\frac{\mathrm{n}_{\beta} \mathrm{e}_{0}(1-\beta)\left[\mathrm{E}-\mathrm{E}^{0^{\prime}}\right]}{\mathrm{k}_{\mathrm{B}} \mathrm{T}}\right)
$$

and

$$
\mathrm{k}_{\operatorname{Red}}(\mathrm{E})=\mathrm{k}^{0} \exp \left(-\frac{\mathrm{n}_{\beta} \mathrm{e}_{0} \beta\left[\mathrm{E}-\mathrm{E}^{0^{\prime}}\right]}{\mathrm{k}_{\mathrm{B}} \mathrm{T}}\right)
$$

Finally, the expression of the rate equation in electrochemical units for the process: Ox $+\mathrm{n}$ e $\leftrightarrow$ Red can be written by making use of the Faraday law:

$$
v=\frac{\mathrm{I}}{\mathrm{nFA}}=\frac{\mathrm{j}}{\mathrm{nF}}=\mathrm{k}_{\mathrm{Ox}}(E) \mathrm{C}_{\mathrm{R}}(0, \mathrm{t})-\mathrm{k}_{\mathrm{Red}} \mathrm{C}_{\mathrm{O}}(0, \mathrm{t})=
$$

where $C_{R}(0, t)$ and $C_{O}(0, t)$ are the concentrations at any time of $O x$ and Red in $x$ $=\mathrm{x}_{2}$, i. e., in the OHP.

$$
=k^{0}\left\{\mathrm{C}_{\mathrm{O}}(0, \mathrm{t}) \exp \left(\frac{\mathrm{n}_{\beta} \mathrm{e}_{0}(1-\beta)\left(\mathrm{E}-\mathrm{E}^{0^{\prime}}\right)}{\mathrm{k}_{\mathrm{B}} \mathrm{T}}\right)-\mathrm{C}_{\mathrm{R}}(0, t) \exp \left(-\frac{\mathrm{n}_{\beta} \mathrm{e}_{0} \beta\left(\mathrm{E}-\mathrm{E}^{0^{\prime}}\right)}{\mathrm{k}_{\mathrm{B}} \mathrm{T}}\right)\right\}
$$


or, by multiplying by the Avogadro number numerator and denominator of the arguments in the exponentials inside the brackets, the equation for the current density, $\mathrm{j}$ is:

$$
j=\mathrm{nFk}^{0}\left\{\mathrm{C}_{\mathrm{O}}(\mathrm{o}, \mathrm{t}) \exp \left(\frac{\mathrm{n}_{\beta}(1-\beta) \mathrm{F}\left(\mathrm{E}-\mathrm{E}^{0^{\prime}}\right)}{R T}\right)-\mathrm{C}_{\mathrm{R}}(0, \mathrm{t}) \exp \left(-\frac{\mathrm{n}_{\beta} \beta \mathrm{F}\left(\mathrm{E}-\mathrm{E}^{0^{\prime}}\right)}{R T}\right)\right\}
$$

Eq. (56) is the called [15] complete current-potential characteristic, used in the treatment of any problem in heterogeneous charge transfer kinetics. It can easily be transformed in the Butler-Volmer equation.

\section{A new definition for the symmetry factor, $\beta$}

The coefficient $\beta$ resulting from the above deduction is defined as the fraction of the whole width of the double layer region, which the electroactive substances must come into in order to allow the tunnelling of the electrons from them to the electrode or from the electrode towards the electroactive substances located at the OHP, i. e., $\beta=a / x_{2}$. This definition coincides with one of the formulations of $\beta$ made by Bockris [23], i. e.:

$$
\beta=\frac{\text { Distance across double layer to summit of the activation barrier }}{\text { Distance across whole double layer }}
$$

Again, $\beta$ can be defined from Eq. (45) by taking logarithms and deriving:

$$
\beta=-\frac{\mathrm{kT}}{\mathrm{n}_{\beta} \mathrm{e}_{0}}\left(\frac{\partial \ln \mathrm{Z}_{\mathrm{Red}}(\Delta \varphi)}{\partial \Delta \varphi}\right)_{T}
$$

or:

$$
\beta=-\frac{\mathrm{RT}}{\mathrm{n}_{\beta} \mathrm{F}}\left(\frac{\partial \ln \mathrm{Z}_{\mathrm{Red}}(\mathrm{E})}{\partial \mathrm{E}}\right)_{\mathrm{T}, \mathrm{E}^{*}}
$$

with the meaning that $\beta$ is proportional to the rate of variation of the logarithm of the frequency factor with the potential. For $\beta=0.5,\left(\frac{\partial \ln \mathrm{Z}_{\mathrm{Red}}(\mathrm{E})}{\partial \mathrm{E}}\right)_{\mathrm{T}, \mathrm{E}^{*}}=$ $-\frac{\beta}{\frac{\mathrm{RT}}{\mathrm{n}_{\beta} \mathrm{F}}} \approx-19.48 \mathrm{n}_{\beta} \mathrm{V}^{-1}$, or: $\left(\frac{\partial \log _{10} \mathrm{Z}_{\mathrm{Red}}}{\partial \mathrm{E}}\right)_{\mathrm{T}=25^{\circ} \mathrm{C}, \mathrm{E}^{*}}=8.4 \mathrm{n}_{\beta} \mathrm{V}^{-1}$, predicting, for $\beta=$ constant $=0.5$, a variation of $Z_{\text {Red }}$ of 8 orders of magnitude for 1 Volt of variation in the potential, or one order of magnitude for each $120 \mathrm{mV}$ of variation in the potential.

In a similar way, from Eq. (32): 


$$
(1-\beta)=\frac{\mathrm{RT}}{\mathrm{n}_{\beta} \mathrm{F}}\left(\frac{\partial \ln \mathrm{Z}_{\mathrm{Ox}}(\mathrm{E})}{\partial \mathrm{E}}\right)_{T, \mathrm{E}^{*}}
$$

An extension of this treatment could include the possibility that, the penetration distance, a, could be a function of the overpotential $(a=f(\eta))$, which would lead to a value of $\beta$ linearly dependent of the applied potential.

\section{Theoretical estimation of the values of $k^{0}$ for some outer sphere electron transfer reactions}

Eqs. (47) and (48) (as well as Eqs. (51)) predict that the exchange rate constant for outer-sphere electron transfer will depend on the nature of the metallic electrode utilised in the study through the presence of $\rho_{M}\left(E_{F}\right)$, the density of states at the Fermi level. This result is the same as the found in other works before (see, for instance Eq. 6.19 in Ref. [4], or Eq. 8.6 in Ref. [24] .The density of electronic levels at the Fermi level is rather similar in different metals [25], with values of $0.27,0.21,0.27,0.27,0.42,0.63$ and 0.50 levels/eV, for $\mathrm{Au}, \mathrm{Cu}$, $\mathrm{Ag}, \mathrm{Fe}, \mathrm{Hg}, \mathrm{Pb}$ and $\mathrm{Pt}$, respectively, at $\mathrm{T}=298 \mathrm{~K}$, so that most of the changes in $\mathrm{k}^{0}$ induced by variations in $\rho_{\mathrm{M}}\left(\mathrm{E}_{\mathrm{F}}\right)$ would be comprised within the range of the experimental errors made during the electrochemical measurements. This can explain the constancy found of the experimental values of $\mathrm{k}^{0}$ measured for outersphere electron transfers on different metals, although this is a matter under discussion [2].

It is possible to obtain theoretical values for $\mathrm{k}^{0}$ from Eq. (51), by making use of the values of $\lambda_{0}, \lambda_{\mathrm{i}}$ and $\Delta \mathrm{G}^{*}{ }_{\text {th }}=\frac{\lambda_{0}+\lambda_{i}}{4}$ given in Ref. ${ }^{[16]}$ and the values of $\rho_{\mathrm{M}}\left(\mathrm{E}_{\mathrm{F}}\right)$ deduced from the equations given in Ref [25]. For instance, the experimental value of $\mathrm{k}^{0}$ measured for the couple $\left[\mathrm{Cr}\left(\mathrm{H}_{2} \mathrm{O}\right)_{6}\right]^{+2 /+3}$ on the Dropping Mercury Electrode (DME) at $\mathrm{T}=298 \mathrm{~K}$ was $1.4 \times 10^{-5} \mathrm{cms}^{-1}[27]$ and $\beta$ $=0.45$. Therefore, the factor $\frac{\pi}{\sin \beta \pi}=\frac{\pi}{\sin 0.45 \pi}=1.01 \pi$. Using now the values: $\rho_{\mathrm{M}}\left(\mathrm{E}_{\mathrm{F}}\right)$ for $\mathrm{Hg}$ at $298 \mathrm{~K}=0.42$ levels $/ \mathrm{eV},\left(\mathrm{k}_{\mathrm{B}} \mathrm{T}\right)=0.026 \mathrm{eV}$ for the temperature cited, $\left(\frac{\mathrm{k}_{\mathrm{B}} T}{2 \pi \mathrm{m}}\right)^{1 / 2}=\left(\frac{R \mathrm{~T}}{2 \pi \mathrm{M}}\right)^{1 / 2}=4963 \mathrm{cms}^{-1}$ for $\mathrm{m}=\frac{160 \mathrm{~g} / \mathrm{mol}}{\mathrm{N}_{\mathrm{A}}}$ (where $\mathrm{N}_{\mathrm{A}}=$ Avogadro's number) in the ion concerned and a value of $\Delta \mathrm{G}^{*}{ }_{\text {th }}=0.432 \mathrm{eV}$ from Ref. [16] and applying this values in Eq. (51), a theoretical value for $\mathrm{k}^{0}$ is deduced of $1.1 \times 10^{-5} \mathrm{cms}^{-1}$ rather close to the experimental one.

Other calculations can be made taking the values of Hale for $\Delta \mathrm{G}^{*}{ }_{\text {th }}$ [16] and $\rho_{\mathrm{M}}\left(\mathrm{E}_{\mathrm{F}}\right)$ [25] and applying Eq. (51). The following cases show higher discrepancies between the experimental and the theoretical values of $\mathrm{k}^{0}$ (for instance in $\left[\mathrm{V}\left(\mathrm{H}_{2} \mathrm{O}\right)_{6}\right]^{2+/ 3+} \mathrm{k}_{\text {exp }}^{0}=4 \times 10^{-3}, \mathrm{k}_{\text {th }}^{0}=3.5 \times 10^{-5}$, in $\left[\mathrm{Mn}\left(\mathrm{H}_{2} \mathrm{O}\right)_{6}\right]^{2+/ 3+} \mathrm{k}^{0}{ }_{\exp }$ $=6 \times 10^{-4}, \mathrm{k}_{\text {th }}^{0}=2 \times 10^{-6}$, in $\left[\mathrm{Fe}\left(\mathrm{H}_{2} \mathrm{O}\right)_{6}\right]^{2+/ 3+} \mathrm{k}_{\text {exp }}^{0}=5 \times 10^{-3}, \mathrm{k}_{\text {th }}^{0}=1.4 \times 10^{-5}$, in $\left[\mathrm{Co}\left(\mathrm{H}_{2} \mathrm{O}\right)_{6}\right]^{2+/ 3+} \mathrm{k}_{\text {exp }}^{0}=1.8 \times 10^{-7}, \mathrm{k}_{\text {th }}^{0}=4.2 \times 10^{-5}$, all values in $\left.\mathrm{cms}^{-1}\right)$. Nonetheless, these discrepancies can be attributed to the fact that many of the experimental 
results should be corrected with respect to the presence of a coulombic double layer effect [26].

On the meaning of the term $\left(\frac{\mathrm{k}_{\mathrm{B}} T}{2 \pi \mathrm{m}}\right)^{1 / 2}$

An interpretation of the term $\left(\frac{\mathrm{k}_{\mathrm{B}} T}{2 \pi \mathrm{m}}\right)^{1 / 2}$ can be given by writing it as the product:

$$
\left(\frac{\mathrm{k}_{\mathrm{B}} T}{2 \pi \mathrm{m}}\right)^{1 / 2}=\frac{k_{B} T}{h}\left(\frac{\mathrm{h}^{2}}{2 \pi \mathrm{m} \mathrm{k}_{\mathrm{B}} T}\right)^{1 / 2}
$$

where the term: $\frac{k_{B} T}{h}$ has dimensions of $\mathrm{s}^{-1}$ (at $\mathrm{T}=298 \mathrm{~K}$ this term presents a value of $6.2 \times 10^{12} \mathrm{~s}^{-1}$ ) and $\left(\frac{\mathrm{h}^{2}}{2 \pi \mathrm{mk}_{\mathrm{B}} T}\right)^{1 / 2}$ has dimensions of a length (for [Fe $\left.\left(\mathrm{H}_{2} \mathrm{O}\right)_{6}\right]^{+3 /+2}$ this term has a value of $7.9 \times 10^{-10} \mathrm{~cm}$, so that the product gives: $\left(\frac{\mathrm{k}_{\mathrm{B}} T}{2 \pi \mathrm{m}}\right)^{1 / 2}=4898 \mathrm{cms}^{-1}$ ) and, considering that the partition function for a particle that experiments a translation in a unidimensional box of length a is given [28] by:

$$
Z_{t}=\left(\frac{2 \pi \mathrm{m} \mathrm{k}_{\mathrm{B}} T}{h^{2}}\right)^{1 / 2} a
$$

then:

$$
\left(\frac{\mathrm{k}_{\mathrm{B}} T}{2 \pi \mathrm{m}}\right)^{1 / 2}=\frac{k_{B} T}{h} \frac{\mathrm{a}}{\mathrm{Z}_{\mathrm{t}}}
$$

On the other hand, remembering that for a homogeneous charge transfer reaction, the frequency factor, $Z_{\text {hom }}$ is given by:

$$
Z_{\text {hom }}=\kappa \frac{\mathrm{k}_{\mathrm{B}} T}{h}
$$

the ratio between $Z_{\text {hom }}$ and $Z_{\text {het }}$ would be:

$$
\begin{aligned}
& \frac{Z_{h e t}\left(c m s^{-1}\right)}{Z_{\text {hom }}\left(s^{-1}\right)}=\frac{\mathrm{a}}{Z_{\mathrm{t}}} \frac{\pi}{\sin \beta \pi} \rho_{M}\left(E_{F}\right)\left(k_{B} T\right)= \\
= & \left(\frac{h^{2}}{2 \pi \mathrm{m} \mathrm{k}_{\mathrm{B}} T}\right)^{1 / 2} \frac{\pi}{\sin \beta \pi} \rho_{\mathrm{M}}\left(E_{F}\right)\left(k_{B} T\right)(\mathrm{cm})
\end{aligned}
$$


and substituting characteristic values in Eq. (65), the ratio between both frequency factors can take values ranging between around 3 to $5 \times 10^{-11} \mathrm{~cm}$.

In addition to this, the fact that the frequency factor is an exponential function of the distance of penetration into the double layer region can be put in relation with results obtained on the distance dependence of the preexponential factors found after Arrhenius analysis of rate constants measured in electron transfer kinetics through alkanethiol monolayers on gold [29].

\section{Conclusions}

The fundamental equation of the electrochemistry has been derived following classical statistical mechanist arguments, going from the supposition that the frequency factor, instead the activation energy, is the magnitude dependent of the potential. Such potential dependence of the frequency factor has been derived by obtaining the Boltzmann distribution of velocities existing inside a space region in which the whole energy of the particles is the sum of a kinetic and an electric component. A new definition of the coefficient $\beta$ results from the treatment, as well as a new theoretical description of the standard rate constant $\mathrm{k}^{0}$, whose values, for electron transfer events studied under adiabatic conditions, are coincident with those obtained from the Marcus- Hush theory.

\section{Acknowledgement}

The author wants to express his thanks to the Ministerio de Ciencia y Tecnología of Spain for a Grant (BQU2002-02522).

\section{APPENDIX}

Solution of the integral: $\int_{-\infty}^{+\infty} \frac{e^{\beta x}}{1+\mathrm{e}^{\mathrm{x}}} d x$ for: $0 \leq \beta \leq 1$.

The above integral can be solved by resorting to the calculus of residues [30]. The convergence of the integral at the limits $\pm \infty$ is made sure by the limits imposed to the value of $\beta$. The integral can be solved in the complex plane by replacing the variable $\mathrm{x}$ by the complex variable $\mathrm{z}$, where $\mathrm{z}=\mathrm{x}+\mathrm{iy}$, and extending the integration around the contour shown in Fig. A.1.

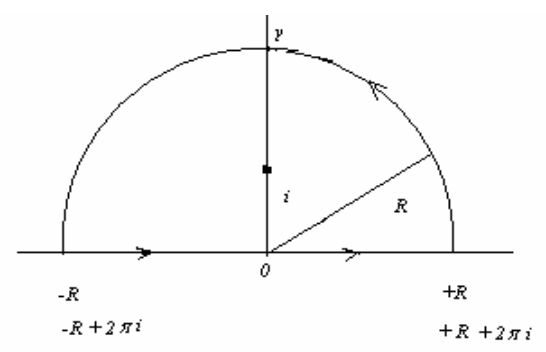

Figure A: 
Integration to the limit $\mathrm{z} \rightarrow \infty$ in the real axis leads to the solution wanted. In addition to this, a return path along $\mathrm{y}=2 \pi$ has to be taken into account in order to leave the denominator of the integrand invariant. Thus, in the complex plane:

$$
\int \frac{e^{\beta z}}{1+\mathrm{e}^{\mathrm{z}}} \mathrm{dz}=\lim _{\mathrm{R} \rightarrow \infty}\left(\int_{-R}^{+R} \frac{e^{\beta x}}{1+\mathrm{e}^{\mathrm{x}}} \mathrm{dx}-\int_{-\mathrm{R}}^{+\mathrm{R}} \frac{\mathrm{e}^{\beta \mathrm{x}} \mathrm{e}^{2 \beta \pi \mathrm{i}}}{1+\mathrm{e}^{\mathrm{x}}} \mathrm{dx}\right)
$$

where, for $\mathrm{z}=\mathrm{x}+2 \pi \mathrm{i}, e^{\beta z}=\mathrm{e}^{\beta \mathrm{x}} \mathrm{e}^{2 \pi \mathrm{i}}$.

Equation A.1 can be rewritten by considering that the factor $\mathrm{e}^{2 \beta \pi \mathrm{i}}=$ constant:

$$
\int \frac{e^{\beta z}}{1+\mathrm{e}^{\mathrm{z}}} \mathrm{dz}=\left(1-\mathrm{e}^{2 \beta \pi \mathrm{i}}\right) \int_{-\infty}^{+\infty} \frac{e^{\beta x}}{1+\mathrm{e}^{\mathrm{x}}} \mathrm{dx}
$$

The contour integral in Eq. A.2 can be evaluated by calculus of residues as:

$$
\frac{1}{2 \pi i} \int \frac{e^{\beta z}}{1+\mathrm{e}^{\mathrm{z}}} \mathrm{dz}=\operatorname{Residue}(\mathrm{f}, \mathrm{i})
$$

Thus, by combining (A.2) and (A.3):

$$
\mathrm{I}=\int_{-\infty}^{+\infty} \frac{e^{\beta x}}{1+\mathrm{e}^{\mathrm{x}}} d x=\left(\frac{2 \pi \mathrm{i}}{1-\mathrm{e}^{2 \beta \pi \mathrm{i}}}\right) \times \operatorname{Residue}(\mathrm{f}, \mathrm{i})
$$

In order to obtain the residue, the integral can be rewritten by resorting to the change of variable: $e^{x}=z^{2} ; 2 \ln z=x ; d x=2 z^{-1} d z=2 e^{-\ln z} d z$. Thus:

$$
\mathrm{I}=\int_{-\infty}^{+\infty} \frac{e^{\beta x}}{1+\mathrm{e}^{\mathrm{x}}} d x=\int_{-\infty}^{+\infty} \frac{e^{2 \beta \ln z}}{1+\mathrm{z}^{2}}\left(2 \mathrm{e}^{-\ln z} d z\right)=2 \int_{-\infty}^{+\infty} \frac{e^{(2 \beta-1) \ln z}}{1+\mathrm{z}^{2}} \mathrm{dz}
$$

A pole is localised in $\mathrm{e}^{\mathrm{z}}=\mathrm{e}^{\mathrm{x}} \mathrm{e}^{\mathrm{iy}}=-1$, i.e., for $\mathrm{z}=0+\mathrm{i} \pi$.

According to the theorem of the principal value of Cauchy:

Residue $=$ (value of the integrand in the singularity multiplied by $\mathrm{z}$ minus the value of $z$ in the singularity, which is $\mathrm{i})=\lim _{z \rightarrow i}($ integrand $)(z-\mathrm{i})$. Thus:

$\operatorname{Re} \operatorname{sidue}(\mathrm{f}, \mathrm{i})=\lim _{\mathrm{z} \rightarrow \mathrm{i}}\left(2 \frac{e^{(2 \beta-1) \ln z}}{(z+\mathrm{i})(\mathrm{z}-\mathrm{i})}\right)(z-\mathrm{i})=$

where the substitution has been made: $1+z^{2}=(z-i)(z+i)$ and taking into account that $\ln z=i \arg z, \quad \lim _{z \rightarrow i}(\ln z)=\lim _{z \rightarrow i}(i \arg z)=\frac{\pi}{2} i($ since, for $z=i, \arg z=\pi / 2)$. In addition, $\lim _{z \rightarrow i}(\mathrm{z}+\mathrm{i})=2 \mathrm{i}$, and $\mathrm{e}^{\pi \mathrm{i}}=-1 ; e^{\frac{\pi}{2} i}=\mathrm{i}=-\mathrm{e}^{-\frac{\pi}{2} i}$ :

$=\lim _{z \rightarrow i}\left(2 \frac{e^{(2 \beta-1) \frac{\pi}{2} i}}{2 i}\right)=\frac{e^{\beta \pi i} \mathrm{e}^{-\frac{\pi}{2} i}}{i}(-1)(-1)=-\frac{e^{\beta \pi i}}{i}\left(\mathrm{e}^{-\frac{\pi}{2} i}\right)\left(e^{\pi i}\right)=\operatorname{Residue}(\mathrm{f}, \mathrm{i})=-\mathrm{e}^{\beta \pi \mathrm{i}}$ 
and, coming back to Eq. A.4:

$\mathrm{I}=\int_{-\infty}^{+\infty} \frac{e^{\beta x}}{1+\mathrm{e}^{\mathrm{x}}} d x=\left(\frac{2 \pi \mathrm{i}}{1-\mathrm{e}^{2 \beta \pi \mathrm{i}}}\right) \times \operatorname{Residue}(\mathrm{f}, \mathrm{i})=\left(\frac{2 \pi \mathrm{i}}{1-\mathrm{e}^{2 \beta \pi \mathrm{i}}}\right)\left(-\mathrm{e}^{\beta \pi \mathrm{i}}\right)=\frac{-2 \pi \mathrm{i}}{\mathrm{e}^{-\beta \pi \mathrm{i}}-\mathrm{e}^{\beta \pi \mathrm{i}}}$

According to Moivre's equations:

and, therefore:

$$
\begin{aligned}
& \mathrm{e}^{\beta \pi \mathrm{i}}=\cos (\beta \pi)+\mathrm{i} \sin (\beta \pi) \\
& \mathrm{e}^{-\beta \pi \mathrm{i}}=\cos (\beta \pi)-\mathrm{i} \sin (\beta \pi)
\end{aligned}
$$

Thus:

$$
e^{-\beta \pi \mathrm{i}}-\mathrm{e}^{\beta \pi \mathrm{I}}=-2 \mathrm{i} \sin (\beta \pi)
$$

$$
\begin{gathered}
\mathrm{I}=\int_{-\infty}^{+\infty} \frac{e^{\beta x}}{1+\mathrm{e}^{\mathrm{x}}} d x=\frac{-2 \pi \mathrm{i}}{-2 \mathrm{i} \sin (\beta \pi)}= \\
=\mathrm{I}=\frac{\pi}{\sin (\beta \pi)}
\end{gathered}
$$

which is the expression used in Eq. (32)

\section{References}

1. R.W. Gurney, Proc. Roy. Soc. London A 134 (1931) 137.

2. $\quad$ N.S. Hush, J. Electroanal. Chem. 470 (1999) 170.

3. A.M. Kusnetzov, J. Ulstrup, Electrochimica Acta 45 (2000) 2239.

4. W. Schmickler, Interfacial Electrochemistry, Oxford University Press, Oxford, 1996.

5. R.J.D. Miller, G.L. McLendon, A.J. Nozik, W. Schmickler, Surface Electron Transfer Processes, VCH, NY, 1996.

6. N.S. Hush, J. Ulstrup, In: A.A. Kornyshev, M. Tosi, J. Ulstrup, (Eds.), Electron and Ion Transfer in Condensed Media, World Scientific, Singapore, 1997.

7. R.A. Marcus, J. Chem. Phys. 24 (1956) 966, 979.

8. $\quad$ N.S. Hush, J. Chem. Phys. 28 (1958) 962.

9. H. Taube, Angew. Chem. Int. Ed. Engl. 23 (1984) 329.

10. M.G. Evans, N.S. Hush, J. Chim. Phys. 49 (1952) 159.

11. J.N. Bronsted, K.N. Pedersen, Z. Phys. Chem. 108 (1924) 185.

12. A.N. Frumkin, Z. Phys. Chem. (A) 160 (1932) 11.

13. J. Tafel, Z. Phys. Chem. 50 (1905) 641.

14. J. Horiuti, M. Polanyi, Acta Physicochim. URRS 2 (1935) 505.

15. A.J. Bard and L.R. Faulkner, "Electrochemical Methods", Wiley, New York 1980.

16. J.M. Hale, "The Rates of Reactions Involving only Electron Transfer at Metal Electrodes", in "Reactions of Molecules at Electrodes", ed. N.S. Hush, Wiley Interscience, London 1971, p 247, Table 4.

17. J. M. Savéant, D. Tessier, Disc. Faraday Soc., Chem. Soc. 74 (1982) 37.

18. E. Kirowa Eisner, M. Schwarz, M. Rosenblum, E. Gileadi, J. Electroanal. Chem. 381 (1995) 29.

19. A.N. Frumkin, Z. Physik. Chem. 164A (1933) 121. 
20. E. Kirowa Eisner, M. Schwarz, M. Rosenblum, E. Gileadi, J. Electroanal. Chem. 361 (1993) 193.

21. S.B. Sachs, S.P. Dudek, R.P. Hsung, L.R. Sita, J.F. Smally, M.D. Newton, S.W. Feldberg and C.E.D. Chidsey, J. Am. Chem. Soc. 119 (1997) 10563.

22. P.H. Atkins, "Physical Chemistry", 6 ${ }^{\text {th }}$ Ed., Oxford University Press, Oxford, Great Britain, 1998.

23. J.O'M. Bockris and A.K.N. Reddy, "Modern Electrochemistry", $1^{\text {st }}$ Ed., page 871. Plenum Press, New York 1970.

24. A.M. Kuznetsov, "Charge Transfer In Physics, Chemistry and Biology. Physical Mechanisms of Elementary Processes and an Introduction to the Theory"; Gordon and Breach Science Ps., 1995.

25. N.W. Ashcroft, N.D. Mermin; "Solid State Physics", CBS Publishing Asia Ltd., 1987.

26. M.J. Weaver, J. Phys. Chem. 84 (1980) 568.

27. R. Parsons, E. Passeron, J. Electroanal. Chem. 12 (1966) 524.

28. I.N. Levine, Physical Chemistry, $5^{\text {th }}$ Ed., Mc Graw Hill, 2003.

29. J.F. Smalley, H.O. Finklea, C.E.D. Chidsey, M.R. Linford, S.E. Creager, J.P. Ferraris, K. Chalfant, T. Zawodzinsk, S.W. Feldberg, M.D. Newton, J. Am. Chem. Soc. 125 (2003) 2004.

30. G. Arfken: "Mathematical Methods for Physicists", $3^{\text {rd }}$ Edition, Academic Press, 1985. 